\title{
A Study on the Functions of Western Cultural Non-Verbal Behavior in English Classroom in China
}

\author{
Yuehong $\mathrm{Wei}^{1}$ \\ ${ }^{1}$ School of Foreign Languages, North China Electric Power University, China \\ Correspondence: Yuehong Wei, School of Foreign Languages, North China Electric Power University, Mailbox \\ 213, No. 689 Huadian Road, Baoding 071003, Hebei, China. Tel: 86-358-222-8281. E-mail: \\ lilywei231@gmail.com
}

Received: September 16, 2013 Accepted: October 26, 2013 Online Published: November 5, 2013

doi:10.5539/elt.v6n12p189 URL: http://dx.doi.org/10.5539/elt.v6n12p189

\begin{abstract}
In China, English classroom is the main place of English language acquisition. Therefore, how to improve English classroom teaching effectively has become the scholars' concern. This paper reports a study conducted at North China Electric Power University on the functions of western cultural nonverbal behaviors in English classroom in China. Questionnaires with both close-ended and open-ended questions were distributed to the students. By means of quantitative and qualitative research methods, this paper analyzed the functions of western cultural nonverbal behaviors in English classroom and found that: 1) as a foreign language teacher you need not only to speak foreign language but also transmit cultural knowledge to students; 2) the nonverbal behaviors which reflect the western culture can have the positive effects on second language learning; 3) Non-verbal behavior should be involved in the teaching and learning processes.
\end{abstract}

Keywords: western culture, functions, nonverbal behavior, English teacher, China

\section{Introduction}

In China, English classroom is the main place of English language acquisition. Therefore, how to improve English classroom teaching effectively has become the scholars' concern. English as a language involves all aspects of language transfer function during the teaching process. In this process, teacher is both the initiator and the user of language which has been the focus of the English classroom all the time. However, in addition to teacher's verbal behavior, we also need to pay attention to nonverbal behavior in the English teaching classroom. Language teaching process is a process of communication, whose primary purpose is to help the students to obtain communicative competence. Language teachers should not only teach the language for the purpose of communication and pay attention to communicative value of all kinds of exercises and methods in the teaching and learning process, but also pay attention to messages conveyed by verbal and nonverbal behavior in the classroom activities. Although verbal behavior is the main carrier of various teaching contents, the auxiliary function of nonverbal behavior is an integral part of communication activities during English classroom teaching. Westernized nonverbal behaviors transfer the culture of the native English speakers for students. In this paper, westernized nonverbal behaviors are discussed separately in order to figure out how much influence the western nonverbal behaviors could have on Chinese English learners in the environment of Chinese English teaching. We should take full use of the functions of western nonverbal behavior in order to improve intercultural communicative competence of Chinese English learners in English teaching.

\section{Literature of Nonverbal Communication}

According to the research, the beginning of study of nonverbal communication comes from the most influential works of Darwin's The Expression of the Emotions in Man and Animals in 1872 (Stacks, 1993; Knapp \& Hall, 1992). The main topic in this book focused on the facial expressions of man and animals, which help biological scientists to investigate underlying feelings and emotions of human beings beneath their behaviors. Another important concept "kinetics" appeared in the book by Ray L. Birdwhistell in 1952, which concept indicated the beginning of the research of nonverbal communication combined with social relationship. That means the nonverbal communication is effective in interpersonal interaction. The term of nonverbal communication is firstly used in a popular book titled Nonverbal Communication: Notes on the Visual Perception of Human Relations by Psychiatrist Jurgen Ruesch and photographer Weldon Kees in 1956. Then, Edward T. Hall studied 
nonverbal communication from the aspect of cross-culture. Nonverbal studies don't belong to any one particular discipline because researchers in such fields as philosophy, psychology, psychiatry, sociology, speech, linguistics, and anthropology have worked on it. Furthermore, the nonverbal communication was introduced to the teaching field and studied by many in researchers during the decades of 1960s. Rosenthal and Jacobson's Pygmalion in the Classroom put forwards that nonverbal behavior in classroom can foster the students' academic achievements (Miller, 1988). From then on, the studies in the classroom field attracted educators' heed. Based on the researches made in 1970s, which mainly focused on the function of nonverbal behavior in human communication, some experts found nonverbal behavior has effective influence on manners of teachers and students in classroom (Woolfolk \& Brooks 1983; 1985). Knapp and Hall (1992) pointed out that nonverbal behaviors can help the speaker constantly give signals about attitudes, feelings, and personality, and help the listener receive, sense and interpret these signals. Mehrabian (1971) claimed that a person's nonverbal behavior has more bearing than his words when transmitting attitudes and feelings.

In the past years, nonverbal communication studies are very significant in many fields focusing on human communication, especially in teaching enviroment (Knapp, 1978; Miller, 1981, 1988; Woolfolk and Brooks, 1985; Malandro, 1989; Richmond, 1991; Burgoon, 1996; Smith, 1979; Woolfolk \& Brooks, 1983; Knapp and Hall, 1992; Neill, 1991 \& 1993 etc.). However, there were seldom studies which explain cultural elements in nonverbal communication or how the differences between the western and eastern nonverbal behaviors work in foreign language teaching environment.

In China, scholars didn't begin their related word as early as the western. The study began in the 1980s and just like in other discipline some scholars translated foreign works on nonverbal communication into Chinese. With the help of the translation books, Chinese researchers who have learned western studies on nonverbal communication have paid more and more heed on the study of nonverbal communication. Later, there are several books written by Chinese scholars, such as, in 1988, Geng Erling published his book titled Introduction about Body Language and Intercultural Nonverbal Communication written by Bi Jiwan and Hu Wenzhong in 1999. Thereafter, the nonverbal research became popular in second language teaching environments. There are some aspects as follows:

\section{1) Researches on nonverbal behavior in intercultural communication}

Liu guilian (2010) interpreted nonverbal communication from the aspect of the semeiology and hold the idea that nonverbal communication is the second semiotic system in human communication and there are some symbols such as gestures, facial expression, body language, and so on, which convey different meanings in different cultures. So we should understand the meanings of them according to different situations concerning cultural elements in order to avoid the conflicts in cross-cultural communication. Wu Xiaoyan (2005) emphasized the importance of nonverbal communication in Cross-cultural Communication holding the idea that nonverbal communication is the essential ability to a foreign language learner and foreign language teacher should teach the differences of nonverbal behaviors between native and target culture so as to deal with conflicts during the cross-culture communication.

\section{2) Researches on nonverbal behavior in language teaching}

Some researchers (Li Wenlan, Lei Tao, 2008; Cui Shujuan, 2010) explained the functions of nonverbal behavior in English language teaching and held the idea that nonverbal behavior can convey the meaning which can not be expressed by verbal behavior. They thought English teacher should guide students to pay attention to the nonverbal behavior in native people's communication and observe the nonverbal behavior directly or teach students something by teacher's own nonverbal behavior. Meanwhile, other researchers pointed out that nonverbal behavior can assist the English teaching effectively and improve the atmosphere in English class and inspire the students' interests.

3) Researches on nonverbal behavior in methodology

Li Hui (2009) did the action research in English classroom reflecting that: there are some differences between male teacher's nonverbal behavior and female teacher's; there is an mutual influence between teacher's nonverbal behavior and students'; students just pay attention to teacher's nonverbal behavior partly. This action research tells us some details about the nonverbal behaviors in English class, which can help English teachers adjust their nonverbal behaviors accordingly, but it did not mention cultural differences between English teacher and other teachers in other majors.

\section{4) Researches on nonverbal behavior in pragmatics}

There are also some researchers (Liu Yulou, 2005, Zheng Juan, Che Yunfang, 2010) make studies from the 
aspects of pragmatics. They used some pragmatics theories to explain the functions of nonverbal behaviors in context of verbal behavior. They paid much attention to the function of nonverbal communication in written form or oral form.

5) Researches on nonverbal behavior in culture

Pan jingling and Shen Huiying (2007) did the research on the connection between culture and nonverbal behavior. They studied the influences of culture on nonverbal behavior. Not like the researchers before, they give insight into different functions of nonverbal behavior in different culture. However, they did not put their ideas in application study.

\section{The Definition of Nonverbal Communication}

When it comes to the definition of nonverbal communication, a set of version can be found as follows. Ronald B. Adler and Nei Towne (1987) define nonverbal communication as "those messages, expressed by other than linguistic means". Samovar \& Porter (2000:149) propose that nonverbal communication involves all those nonverbal stimuli in all communication settings that are generated by both the source and his or her use of the environment and that have potential message value for the source or receiver. In the above definition, they both highlight the function of nonverbal communication and all the elements related communication.

Among the experts, Miller (1988) gave a comprehensive definition of nonverbal communication. He synthesized the definition of several researchers when he stated "nonverbal communication has been defined as communication without words..."Miller also asserted "It includes overt behaviors such as facial expressions, eyes, touching and tone of voice, as well as less obvious messages such as dress, posture, and spatial distance between two or more people." It tells specific details included in the meaning of "nonverbal". Miller indicated that nonverbal communication is learned shortly after birth, is practical and refined throughout a person's life. It means the nonverbal behavior can be trained in the later education. Nonverbal communication is complex, for it is both behavior and communication, intentional or unintentional. Therefore, we must lean the nonverbal behavior while we learn language which plays the main role in communication.

\section{The Classification of Nonverbal Communication}

Michael Argrle (1972) took the Nonverbal communication as the same concept as body language, including facial expressions, gaze, gestures and bodily movements, postures, bodily contact, spatial behavior, clothes, physique and other aspects of appearance and nonverbal vocalizations. There are some other experts put it into another way like He Daokuan (1988), he divided nonverbal communication into the following categories as: Time language; Space language: body touch and personal distance; Body language: posture, gestures, facial expressions, eye behavior, any other movement of any part of body and appearance; Voice modulation: speed, pitch, volume, pause, etc. In the 1990s, researchers developed the classification and added the environmental elements. Knapp (1997) and Bi Jiwan (1999) put forward that nonverbal behaviors can be classified into the following three types: body language, paralanguage and environment language. In the following discussion, all of them will be included concerning cultural elements.

\section{Nonverbal Behavior and Culture}

Nonverbal behavior reflects the culture and belongs to the culture. In 1964, American linguistics W. Rivers gave his idea from the aspect of foreign language teaching and claimed that foreign language teachers must be qualified in cultural field including knowing about native speakers' behavior, gesture and facial expression. That means nonverbal behavior can help teachers convey cultural knowledge. Generally speaking, nonverbal communication is usually a cultural phenomenon, so we have to relate it to cultural background. Samovar \& Porter (2000:149) propose that nonverbal communication involves all those nonverbal stimuli in all communication settings that are generated by both the source and his or her use of the environment and that have potential message value for the source or receiver. So nonverbal communication can needs the cultural environment or cultural background.

Nonverbal communication is a cultural behavior and can be trained in learning process. Without it you can not communicate with others successfully. In foreign language teaching environment, nonverbal behavior must be one of essential parts which learners must cover, and can help them improve their language skills.

Especially, English teachers must know some native nonverbal behaviors which belong to the western culture. Western nonverbal behaviors can inspire students' language abilities and arouse their interests in English learning process. 


\section{Study on the Functions of Western Cultural Nonverbal Behaviors in English Classroom in China}

\subsection{Research Questions}

In the current research the following three questions will be solved:

1) What are the functions of western cultural nonverbal behaviors in English classroom in China?

2) Are there some positive effects of western cultural nonverbal behaviors in English classroom in China?

3) How to integrate the western cultural nonverbal behavior with the English language teaching?

\subsection{Participants}

The 50 participants, who are the sophomores from the North China Electric University in China, study college English as their compulsory course in non-English majors. They were from two classes divided according to the CET-4. Approximately $80 \%$ of the students were male and $20 \%$ were female, and their age ranged from 18 to 21 .

\subsection{Instruments}

In this study, Questionnaire is used to investigate the specific questions. In order to guarantee the reliability and validity of the questionnaire, a pre-survey on a small scale was carried out to collect feedback opinions after the first draft. According to the feedback opinions collected, appropriate revisions were made. Then the final questionnaires were distributed to the students. In order to ensure the reliability and validity of the survey process, the researcher distributes the questionnaires to the students in their regular class time, and collected them as soon as possible. Meanwhile, questions in the whole questionnaire are to investigate what the functions of western cultural nonverbal behaviors in English classroom are in China. Questionnaire on western cultural nonverbal behaviors was distributed to 50 students. And 40 valid ones were got back. The questionnaire includes 8 items, which were followed by five options ranging from: A to $\mathrm{E}$ : $\mathrm{A}=$ strongly agree, $\mathrm{B}=$ agree, $\mathrm{C}=$ undecided, $\mathrm{D}=$ disagree, to $\mathrm{E}=$ strongly disagree, and three open-ended questions about western cultural nonverbal behaviors are for English classroom in China.

\subsection{Data Collection and Analysis}

\subsubsection{Data Collection}

The questionnaires were carried out to 50 students during the class time. Before they answer the questions, the teacher told the students that the purpose of the study is to help them improve the English learning in class. When the students answered the questionnaire, they were told that they should give the objective answers. After they did them, they turned them in. Finally, there were 45 validate questionnaires. There were only about 26 items for the qualitative data from several aspects (shown in Appendix II) because some students had no idea about the western cultural nonverbal behaviors in English class. Instructions were given in Chinese in order to make sure that students could answer the requirements objectively.

\subsubsection{Data and Result Analysis}

Quantitative data from the questionnaire were entered into Excel and examined for the percentage of the students' choices in the 8 questions for the percentage numbers can tell what the functions of western cultural nonverbal behaviors are in English classroom in China. The qualitative data from the open-ended questions of the questionnaire were used to study the functions of western cultural nonverbal behaviors are in English classroom in China. The qualitative data also provided some useful insights into How to integrate the western cultural nonverbal behavior with the English language teaching.

From the Table 1, there are $57.5 \%$ students who agree that English teachers use the western nonverbal behaviors in English class. In item 2, there are 37.5\% students who can be inspired by English teachers' western nonverbal behaviors and 52.5\% students were not sure about the positive effect of English teachers' western nonverbal behaviors on their English learning. That is to say, westernized nonverbal behaviors have been employed in English class in China, but whether they can improve the students' English learning is not very clear. So the following research items can provide some evidence for this point. In item 3, there are $67.5 \%$ students who hold that English teachers' teaching methods are different from other teachers in other courses, for example, in item 4, $85 \%$ students agree that English teachers are friendly to communicate with students; in item 5, 75\% students agree English teachers' cadences of speech can attract their attention; in item 6, 80\% students agree that they can show their own ideas in English class through various class activities arranged by English teachers; in item 7, 82.5\% students hold that English teachers are addressed fashionably, properly and leisurely; in item 8, 80\% students think that English teachers pay attention to their response to the lecture and have the eye contact with the them. 
Table 1. English teachers' nonverbal behaviors

\begin{tabular}{lllllll}
\hline No. & Items & $\mathrm{A}$ & $\mathrm{B}$ & $\mathrm{C}$ & $\mathrm{D}$ & $\mathrm{E}$ \\
\hline 1 & $\begin{array}{l}\text { English teachers often use the western } \\
\text { nonverbal behaviors in English class }\end{array}$ & $12.5 \%$ & $45.0 \%$ & $37.5 \%$ & $5.0 \%$ & $0 \%$ \\
2 & $\begin{array}{l}\text { English teachers western nonverbal } \\
\text { behaviors can inspire our English learning } \\
3\end{array}$ & $10.0 \%$ & $27.5 \%$ & $52.5 \%$ & $7.5 \%$ & $2.5 \%$ \\
$\begin{array}{l}\text { Teaching methods used by English } \\
\text { teachers are different from those used by } \\
\text { teachers in charge of other subjects }\end{array}$ & $12.5 \%$ & $55.0 \%$ & $30 \%$ & $2.5 \%$ & $0 \%$ \\
4 & $\begin{array}{l}\text { English teachers are friendly and like to } \\
\text { communicate with students }\end{array}$ & $30.0 \%$ & $55.0 \%$ & $12.5 \%$ & $2.5 \%$ & $0 \%$ \\
5 & $\begin{array}{l}\text { English teachers' cadences of speech can } \\
\text { attract their attention }\end{array}$ & $\begin{array}{l}\text { English teachers arrange various activities } \\
\text { in which you can show your ideas in }\end{array}$ & $65.0 \%$ & $20 \%$ & $2.5 \%$ & $2.5 \%$ \\
7 & $\begin{array}{l}\text { English class } \\
\text { English teachers are addressed fashionably, 17.5\% } \\
\text { properly and leisurely }\end{array}$ & $65.0 \%$ & $15 \%$ & $12.5 \%$ & $0 \%$ \\
\hline $\begin{array}{l}\text { English teachers pay attention to the } \\
\text { students' response and have the eye } \\
\text { contact with the Students }\end{array}$ & $22.5 \%$ & $57.5 \%$ & $20 \%$ & $0 \%$ & $0 \%$ \\
\hline
\end{tabular}

Above all, English teachers' nonverbal behaviors are very dramatic. Just as what is like in cultural differences, English teachers must use some western cultural nonverbal behaviors in English teaching process to some extent. In the followings, the functions of western cultural nonverbal behaviors will be discussed.

From table 2, the questions are developed into further discussion as follows: in item 9, 87.5\% students agree that there are some differences between the English teachers and teachers in other courses and they provide some tips on the differences:

1) There are some differences, such as body language can improve the learning interests; multimedia frequently used in English teaching; eye contacts in class; gestures; dramatic, vivid and attractive gestures;

2) There are few differences except for more walking back and forth in English classroom, easier communication, more natural body language.

3) There is no difference except for language difference because they are all Chinese.

I never pay attention to teacher body language and I have no idea about what the western cultural nonverbal behaviors are.

In item 10,90\% students hold that English teachers' nonverbal behaviors can transmit the western culture and they also provide some tips on "how to":

1) English teachers' nonverbal behaviors can transmit the western culture by playing education movies in English and using western cultural nonverbal behaviors to interpret the western culture.

2) Western culture can be transmitted only by language not by nonverbal behavior.

3) I have no idea about it and it is no use for English learning.

In item $11,75 \%$ students hold that western cultural nonverbal behavior can really improve their English learning and some of them give their opinions on "how to":

1) Western cultural nonverbal behavior can really improve their English learning by attracting students' attention, knowing more about western culture, providing English learning and communication atmosphere and strengthening the memories.

2) Western cultural nonverbal behavior is not somehow helpful to improve their English learning and I did not feel it at all. 
Table 2. The functions of western cultural nonverbal behaviors in English class

\begin{tabular}{llllll}
\hline No. & Questions & Agree & Not agree & Uncertain & Answer Tips \\
\hline 9 & $\begin{array}{l}\text { Do you think there are some differences } \\
\text { between the English teachers and teachers } \\
\text { in other courses? What are they? }\end{array}$ & $42.5 \%$ & $45.0 \%$ & $12.5 \%$ & shown in Appendix II \\
10 & $\begin{array}{l}\text { Do you think English teachers' nonverbal } \\
\text { behaviors can transmit the western } \\
\text { culture? How do they transmit it? }\end{array}$ & $55 \%$ & $35 \%$ & $10.00 \%$ & shown in Appendix II \\
11 & $\begin{array}{l}\text { Do you think western cultural nonverbal } \\
\text { behavior can really improve their English } \\
\text { learning? How do they improve it? }\end{array}$ & & $25 \%$ & shown in Appendix II \\
\hline
\end{tabular}

\section{Conclusion}

According to the above survey, the functions of western cultural nonverbal behaviors in English classroom in China have been found, such as attracting the students' attention, transmitting culture, improving language learning and cross cultural communication. As a foreign language teacher, you need not only to speak foreign language but also transmit cultural knowledge to students. So the nonverbal behaviors which reflect the western culture can have the positive effects on second language learning. Firstly, English teacher must know more about western culture especially imitating their nonverbal behaviors which imply the cultural differences. Secondly, they should add those nonverbal behaviors into their teaching process naturally and influence or inspire students' English learning accordingly. Thirdly, some evaluation tasks related to western culture should employed to test the teachers' nonverbal behaviors in English classroom.

Compared with the traditional English classroom in China, researchers pay more attention to teachers' nonverbal behaviors reflecting the western culture and regard it as one of the criteria to evaluate teachers' performances. Students learn English with the purpose to do the cross-cultural communication with foreigners, so they also should pay more attention to the knowledge related to the western cultural in the learning process. Western culture can be transmitted by language and also by nonverbal behaviors vividly which can attract the learner's attention.

There are some weaknesses in the current study and the outcomes of the current study imply a number of questions for further research:

1) The current survey only investigate the small number of students, which may influence the reliability of the result; the development of a larger scale survey investigating the functions of western cultural nonverbal behaviors in English classroom in China is required.

2) There are only one investigation on the functions of western cultural nonverbal behaviors in English classroom and didn't carry out a teaching process to integrate the western cultural nonverbal behavior with the English language teaching in the research. Hence, how teachers can integrate the western cultural nonverbal behavior with the English language teaching is still a problem to solve in China, since most teachers in Chinese colleges only pay attention to their language teaching process?

3) The western cultural nonverbal behaviors include many aspects, such as, Time language; Space language: body touch and personal distance; Body language: posture, gestures, facial expressions, eye behavior, any other movement of any part of the body and appearance; Voice modulation: speed, pitch, volume, pause, etc. Since this study did not cover all of them, more comprehensive researches are supposed to be done.

\section{Acknowledgments}

This research was supported by Social Sciences Fund of Hebei Province (Grant \# HB11Y0121).

\section{References}

Argyle, Michael, \& Hinde, R. A. (1972). Non-verbal communication in human social interaction. Non-verbal communication (p. 443). Oxford, England: Cambridge U. Press.

Burgoon, J., Buller, D. B., \& Woodall, W. G. (1996). Nonverbal Communication. New York: MicGraw-Hill, Inc.

Erling Geng. (1988). Introduction about Body Language. Beijing: Beijing Language and Culture University Press.

Galloway, C. (1979). Teaching and nonverbal behavior. New York: Academic Press. 
Knapp, M. L. (1978). Nonverbal Communication in Human Interaction (2nd ed.). Orlando: Holt, Rinehart and Winston, Inc.

He Daokuan. (1988). Nonverbal Communication. Shanghai: Shanghai Translation Publishing Press.

Hui Li. (2009). An Action Research on Classroom Nonverbal Behaviors of College English Teachers. M.D. Thesis, Northwest Normal University.

Jingling Pan, \& Huiying Shen. (2007). Culture and Nonverba1 Communication. Journal of Bilingual learning, 9 , 144-145.

Knapp, M., \& Hall, J. (1992). Nonverbal Communication in Human Interaction (3rd ed.). New York: Forth Worth, TX: Harcourt Brace.

Malandro, L. A., Barker, L. L., \& Barker, D. A. (1989). Nonverbal Communication. New York: Random House.

Mehrabian, A. (1971). Silent Messages. Belmont, CA: Wadsworth.

Miller, P. W. (1981). Nonverbal Communication. Washington, D.C.: National Education Association.

Miller, P. (1988). Nonverbal Communication: What Research Says to the Teacher (3rd ed.). Washington DC: National Educational Association.

Neill, S. (1991). Classroom Nonverbal Communication. London \& New York: Routledge.

Neill, S., \& Caswell, C. (1993). Body Language for Competent Teachers. London: Routledge.

Richmond, V. P., et al. (1991). Nonverbal Behavior in Interpersonal Relations. Englewood Cliffs, NJ: Prentice Hall.

Samovar, Larry A., \& Richard E. Porter. (2000). Communication between Cultures. Beijing: Foreign Language Teaching and Research Press.

Shujuan Cui. (2010). The Application of Nonverbal Communication in College English classroom. Journal of Nanchang College of Education, 6, 63-64.

Smith, H. A. (1979). Nonverbal Communication in Teaching. Review of Educational Research, 49(4), 631-672.

Wenlan Li, \& Tao Lei. (2008). Nonverbal Communication and Foreign Languages Teaching. Journal of Xi'an University of Architecture \& Technology, 3, 89-91.

Wenzhong Hu, \& Jiwan Bi. (1999). Intercultural Nonverbal Communication. Beijing: Foreign Language Teaching and Research Press.

Woolfolk, A., \& Brooks, D. (1983). Nonverbal Communication in Teaching and Cultural Implications. New York: Academic Press.

Woolfolk, A., \& Brooks, D. (1985). “The Influence of Teachers' Nonverbal Behaviors on Students' Perceptions and Performance". The Elementary School Journal, 85(4).

Xiaoyan Gao. (2005). The Cultural Differences of Nonverbal Communication and Foreign Languages Teaching. Journal of Anhui Business College of Vocational Technology, 2, 73-74.

Yulou Liu. (2005). The Pragmatic Functions of Nonverbal Behavior. M.D. Thesis, Shangdong University.

Yuxin Jia. (1997). Intercultural Communication. Shanghai: Shanghai Education Press.

\section{Appendices}

Appendix I

There are some questions about your English teacher's nonverbal behaviors, and please choose the proper answer objectively.

1) English teachers often use the western nonverbal behaviors in English class.

A strongly agree, B agree, C undecided, D disagree, E strongly disagree

2) English teachers' western nonverbal behaviors can inspire our English learning.

A strongly agree, B agree, C undecided, D disagree, E strongly disagree

3) Teaching methods used by English teachers are different from those used by teachers in charge of other subjects.

A strongly agree, $\mathrm{B}$ agree, $\mathrm{C}$ undecided, D disagree, E strongly disagree 
4) English teachers are friendly and like to communicate with students.

A strongly agree, B agree, C undecided, D disagree, E strongly disagree

5) English teachers' cadences of speech can attract students' attention

A strongly agree, B agree, $\mathrm{C}$ undecided, D disagree, E strongly disagree

6) English teachers arrange various activities in which you can show your ideas in English class.

A strongly agree, $\mathrm{B}$ agree, $\mathrm{C}$ undecided, $\mathrm{D}$ disagree, E strongly disagree

7) English teachers are addressed fashionably, properly and leisurely

A strongly agree, $\mathrm{B}$ agree, $\mathrm{C}$ undecided, $\mathrm{D}$ disagree, E strongly disagree

8) English teachers pay attention to the students' response and have the eye contact with the Students.

A strongly agree, B agree, $\mathrm{C}$ undecided, D disagree, E strongly disagree

9) Do you think there are some differences between the English teachers and teachers in charge of other subjects? What are they?

10) Do you think English teachers' nonverbal behaviors can transmit the western culture? How do they transmit it?

11) Do you think western cultural nonverbal behavior can really improve their English learning? How do they improve it?

Appendix II

The answers to item 9, item 10 and item 11 listed in the following.

9) Do you think there are some differences between the English teachers and teachers in other courses? What are they?

There are some differences, such as body language can improve the learning interests; multimedia frequently used in English teaching; eye contacts in class; gestures; dramatic, vivid and attractive gestures.

There are few differences except for more walking back and forth in English classroom, easier communication, more natural body language.

There are no differences except for language difference because they are all Chinese.

I never pay attention to teacher body language and I have no idea about what the western cultural nonverbal behaviors are.

10) Do you think whether English teachers' nonverbal behaviors can transmit the western culture? How do they transmit it?

English teachers' nonverbal behaviors can transmit the western culture by playing education movies in English and using western cultural nonverbal behaviors to interpret the western culture.

Western culture can be transmitted only by language not by nonverbal behavior.

I have no idea about it and it is no use for English learning.

11) Do you think whether western cultural nonverbal behavior can really improve their English learning? How do they improve it?

Western cultural nonverbal behavior can really improve their English learning by attracting students' attention, knowing more about western culture, providing English learning and communication atmosphere and strengthening the memories.

Western cultural nonverbal behavior is not somehow helpful to improve their English learning and I did not feel it at all.

\section{Copyrights}

Copyright for this article is retained by the author(s), with first publication rights granted to the journal.

This is an open-access article distributed under the terms and conditions of the Creative Commons Attribution license (http://creativecommons.org/licenses/by/3.0/). 